\title{
Flight Power Scaling of Airplanes, Airships, and Helicopters: Application to Planetary Exploration
}

\author{
Ralph D. Lorenz* \\ University of Arizona, Tucson, Arizona 85721-0092
}

\begin{abstract}
Empirical relations for the required flight power of propeller-driven lighter-than-air and fixed-wing heavierthan-air vehicles are developed purely as a function of vehicle mass and flight speed. A relation for rotary-wing vehicles includes rotor diameter as an additional parameter. For airships, airplanes, and helicopters these relations each span some 6-7 orders of magnitude in power, covering model aircraft and unmanned air vehicles, as well as conventional crewed vehicles. From first principles, these relations are extended to other environments (different gravity and atmospheric density) and allow the rapid and convenient preliminary evaluation of aircraft concepts on this world and others. Results compare favorably with terrestrial birds and submarines.
\end{abstract}

\section{Introduction}

V ARIOUS approaches in estimating the performance of a new aircraft can be adopted, ranging from the simple to the sophisticated. The preliminary design of conventional light or transport aircraft, where production volumes are expected to be significant, typically uses statistical data on previous designs to estimate piecewise the masses, drag increments, and so on, of individual components. ${ }^{1}$ The design process is iterated with some confidence before a prototype is constructed.

Less conventional aircraft, particularly those produced in small volumes and in a nonindustrial environment that is conducive to tinkering (e.g. low-volume production of airships or the design of model aircraft) tend only to have the grossest of parameters specified by experience, such as wing or power loading. Performance is determined almost exclusively by subsequent trial and error.

This paper attempts to bridge these extremes, by consideringmanageably few parameters (specifically those that are readily found in the public domain and as few of those as necessary), yet examining them for as wide a range of parameters as possible. The relations are continuously quantitative, unlike the empiricism of model aircraft typified by statements such as so and so an engine will usually achieve $30 \mathrm{mph}$. On the other hand, unlike the bottom-up approach of specification for conventional aircraft, this paper takes that of lumped ignorance: The performance parameters of vehicles are related directly to each other in a purely empirical fashion, without considering intermediate steps.

This type of study (allometry) has been employed extensively in biology, in particular to study the biophysics of locomotion. Such investigations often shed light on phenomena that are otherwise difficult to grapple with by virtue of the system's complexity, such as under which circumstances one mode of locomotion is more efficient than another. In this vein, this paper considers airships and helicopters as well as airplanes (see Ref. 3 which considers a wider range of vehicles, but in less detail).

In the present paper relations are developed by pure empirical fitting of the dependence of required power on vehicle mass and speed. These are compared with the expected dependencies from first principles and thereby extended to other environments. They are then applied to other planetary environments to determine the suitability or required power of various aerial vehicles for planetary exploration.

Received 5 March 2000; revision received 15 September 2000; accepted for publication 13 October 2000. Copyright (C) 2000 by the American Institute of Aeronautics and Astronautics, Inc. All rights reserved.

* Senior Research Associate, Lunar and Planetary Laboratory.

\section{Fixed-Wing Heavier-Than-Air Vehicles}

A. Theoretical Power for Airplanes

In steady level flight, the following relation applies:

$$
m g=0.5 \rho \cdot S C_{L} V^{2}
$$

with $m$ the vehicle mass, $g$ local gravitational acceleration, $\rho$ the ambient air density, $S$ the wing reference area, $V$ the flight speed, and $C_{L}$ the lift coefficient. The flight power is given by

$$
P=D V=m g V \cdot\left(C_{D} / C_{L}\right)
$$

Thus, the flight power $P$ is proportional to the mass, gravity, and flight speed, while inversely proportionalto the lift-to-dragratio. An interesting corollary is that, all else being equal, the energy cost of travel is independentof flight speed. Note that this is the rate at which energy is supplied to the directed airstream for propulsion (assumed in this study by a propeller); the actual shaft power required will be somewhat higher.

There are of course penalties in lift-to-drag ratio at very low speed (Reynolds number) and at high speed (Mach number). These are subsumed under the mass and speed dependencies in this study.

For the vehicles considered, thrust is developed by propellers. Although no explicit dependence of flight power on fluid density appears in the preceding equations, the speed and, hence, power of the propulsive airstream depends on the fluid density. When the effect of flight speed is ignored, the actuator disk equation shows

$$
P=T^{1.5} / \sqrt{2 \rho \cdot A}
$$

where $T$ is the static thrust and $A$ the disk area. Thus, for a given vehicle to produce a given thrust, that is, to compensate the vehicle's drag for a given vehicle mass and flight speed, the power varies as $\rho^{-0.5}$, all else being equal. It may be that in fluids of different density the disk area is scaled: However, in this paper we will leave this dependence as a free parameter because the propulsion scaling depends on issues such as tip Mach number and cavitation effects.

\section{B. Actual Flight Power Airplanes}

Figure 1 shows the installed engine power of a range of aircraft, against their maximum takeoff mass and maximum flight speed. Note that the human-powered aircraft Gossamer Albatross entry is shown circled and does not (unsurprisingly) fall with the other data. The data are summarized in Table 1 (see Refs. 4-8). Note that whereas a wide range of masses and powers is considered, all of the vehicles are propeller-drivenmonoplanes (with the exception of the micro-air vehicle (MAV), which is a biplane).

Although Eq. (2) describes the variation of power reasonably well, regression of these data indicates that power is proportional to 
Table 1 HTA fixed-wing vehicles

\begin{tabular}{|c|c|c|c|c|c|}
\hline Vehicle & Mass, kg & Speed, m/s & Power, W & Comment & Reference \\
\hline MAV & $1.50 E+00$ & 24.6 & $5.15 E+02$ & Micro-air-vehicle & 4 \\
\hline Pointer & $3.60 E+00$ & 22.3 & $7.00 E+02$ & UAV & $-^{\mathrm{a}}$ \\
\hline Ryan RPV-007 & $5.40 E+00$ & 58.1 & $1.62 E+03$ & UAV & 5 \\
\hline DH Enmoth & $1.13 E+01$ & 36.3 & $1.47 E+03$ & UAV & 5 \\
\hline Aerosonde & $1.32 E+01$ & 28.6 & $7.35 E+02$ & Environmental UAV & 6 \\
\hline RCS Falcon & $1.63 E+01$ & 56.7 & $7.35 E+03$ & Target & 5 \\
\hline Aerospatiale D15 & $1.80 E+01$ & 55.6 & $2.50 E+03$ & Target & 5 \\
\hline Luna & $2.00 E+01$ & 50.1 & $4.41 E+03$ & Military UAV & 6 \\
\hline Eglen Falcon & $2.27 E+01$ & 51.4 & $2.21 E+03$ & UAV & 5 \\
\hline RCS Heron & $2.40 E+01$ & 53.6 & $7.35 E+03$ & UAV & 5 \\
\hline DSI Scout & $2.50 E+01$ & 30.8 & $1.47 E+03$ & Experimental & 5 \\
\hline Mini-Vanguard & $3.60 E+01$ & 49.2 & $1.84 E+04$ & Military UAV & 6 \\
\hline APL RPD2 & $3.63 E+01$ & 77.2 & $8.82 E+03$ & Target & 5 \\
\hline Vigilant & $4.00 E+01$ & 26.8 & $8.82 E+03$ & Military UAV & 6 \\
\hline Exdrone & $4.10 E+01$ & 44.7 & $5.88 E+03$ & Military UAV & 6 \\
\hline Shorts MATS-B & $4.54 E+01$ & 64.2 & $9.19 E+03$ & UAV & 5 \\
\hline Aquila & $5.44 E+01$ & 60.8 & $8.09 E+03$ & UAV & 5 \\
\hline DSI Skyeye & $5.66 E+01$ & 61.7 & $8.82 E+03$ & UAV & 5 \\
\hline Praerie & $6.12 E+01$ & 38.1 & $5.88 E+03$ & UAV & 5 \\
\hline Porter & $9.10 E+01$ & 33.5 & $1.62 E+04$ & Military UAV & 6 \\
\hline Gossamer Albatross & $1.10 E+02$ & 5.1 & $1.62 E+02$ & Human-powered aircraft & 7 \\
\hline Vanguard & $1.06 E+02$ & 69.3 & $1.25 E+04$ & Military UAV & 8 \\
\hline Phela & $1.30 E+02$ & 50.1 & $2.35 E+04$ & Military UAV & 8 \\
\hline Dragon & $1.50 E+02$ & 50.1 & $2.57 E+04$ & Military UAV & 8 \\
\hline Halifax & $1.59 E+02$ & 53.6 & $2.79 E+04$ & Military UAV & 8 \\
\hline Falconer & $2.00 E+02$ & 89.7 & $6.76 E+04$ & Military UAV & 5 \\
\hline Sperwer & $2.50 E+02$ & 69.3 & $5.15 E+04$ & Military UAV & 6 \\
\hline Ranger & $2.75 E+02$ & 61.2 & $3.09 E+04$ & Military UAV & 6 \\
\hline Hermes 450 & $4.54 E+02$ & 51.4 & $5.59 E+04$ & Military UAV & 6 \\
\hline Skyeye & $5.68 E+02$ & 55.9 & $3.82 E+04$ & Military UAV & 6 \\
\hline Robin ATL & $5.80 E+02$ & 55.4 & $4.78 E+04$ & Single prop light aircraft & 8 \\
\hline Robin HR400 & $9.00 E+02$ & 67.0 & $8.23 E+04$ & Single prop light aircraft & 8 \\
\hline Commander & $1.27 E+03$ & 77.3 & $1.47 E+05$ & Single prop light aircraft & 8 \\
\hline Robin HR100 & $1.40 E+03$ & 87.6 & $1.32 E+05$ & Single prop light aircraft & 8 \\
\hline Saratoga & $1.63 E+03$ & 78.2 & $2.21 E+05$ & Twin engine light aircraft & 8 \\
\hline Commanche & $1.69 E+03$ & 121.6 & $2.35 E+05$ & Twin engine light aircraft & 8 \\
\hline Malibu & $1.95 E+03$ & 122.0 & $2.57 E+05$ & Twin engine light aircraft & 8 \\
\hline Seneca & $2.07 E+03$ & 100.6 & $2.94 E+05$ & Twin engine light aircraft & 8 \\
\hline Pilatus PC-12 & $4.00 E+03$ & 123.4 & $1.18 E+06$ & Twin engine light aircraft & 8 \\
\hline Cheyenne & $4.08 E+03$ & 145.3 & $9.11 E+05$ & Twin engine light aircraft & 8 \\
\hline Beechcraft B99 & $4.84 E+03$ & 127.4 & $10.00 E+0$ & Twin prop transport & 8 \\
\hline Jetstream 41 & $1.09 E+04$ & 152.0 & $2.36 E+06$ & Twin prop transport & 8 \\
\hline DC-3 & $1.14 E+04$ & 102.4 & $1.76 E+06$ & Twin prop transport & 8 \\
\hline Sherpa & $1.16 E+04$ & 99.7 & $2.09 E+06$ & Twin prop transport & 8 \\
\hline $\mathrm{DH}-4$ & $1.29 E+04$ & 96.5 & $2.13 E+06$ & Twin prop transport & 8 \\
\hline Airtech CN235 & $1.65 E+04$ & 123.4 & $2.57 E+06$ & Twin prop transport & 8 \\
\hline ATR 42 & $1.67 E+04$ & 138.6 & $2.65 E+06$ & Twin prop transport & 8 \\
\hline Bae 748 & $2.11 E+04$ & 125.6 & $3.35 E+06$ & Twin prop transport & 8 \\
\hline An-30 & $2.30 E+04$ & 149.7 & $3.75 E+06$ & Transport & 8 \\
\hline ATP & $2.37 E+04$ & 139.4 & $4.04 E+06$ & Twin prop transport & 8 \\
\hline An-32 & $2.70 E+04$ & 147.0 & $7.41 E+06$ & Transport & 8 \\
\hline Alenia G-222 & $2.80 E+04$ & 135.4 & $5.00 E+06$ & Transport & 8 \\
\hline Transall C160 & $5.10 E+04$ & 142.6 & $8.97 E+06$ & Transport & 8 \\
\hline An-12 & $6.10 E+04$ & 215.4 & $1.31 E+07$ & Transport & 8 \\
\hline C-130 & $7.03 E+04$ & 167.2 & $1.33 E+07$ & Transport & 8 \\
\hline An-70 & $1.30 E+05$ & 222.1 & $4.06 E+07$ & Transport & 8 \\
\hline An-22 & $2.50 E+05$ & 205.6 & $4.41 E+07$ & Transport & 8 \\
\hline
\end{tabular}

${ }^{a}$ URL:http:www.aerovironment.com/area-aircraf+/prod-serv/pointer. html.

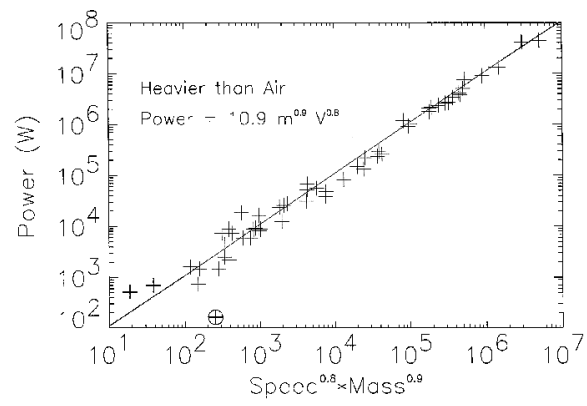

Fig. 1 Installed power of propeller-driven HTA aircraft against a bestfit parameter depending on speed and mass. the 0.9 th power of mass and the 0.8 th power of speed. This result is reassuringly close to the linear relation expected on given theoretical grounds and probably indicates the slight economies introduced, presumably due to factors such as Reynolds number effects and increased propulsive efficiency, in larger, faster vehicles.

To generalize the fit to other environments, we may include the environmental dependence, $g$, from Eq. (2) with the given fit. It is likely (see preceding text and Sec. V) that an effect due to the propulsive efficiency of a given sized propeller in a fluid of different density also needs to be applied. Notionally, in a more dense fluid, a smaller propeller is preferable; the size of marine propellers relative to the vehicle as a whole is smaller than that of aircraft. Structural considerations, tip Mach number, and cavitation are all possible concerns that defy obvious simple quantification. Accordingly, we 
parameterize the density scaling of propulsive efficiency as $n$, with $n<0<1$ [where 0 is no effect on propulsive efficiency and 1 is as in Eq. (3)], leading to

$$
P=10.9 m^{0.8} V^{0.9}\left(g / g_{e}\right)\left(\rho / \rho_{e}\right)^{-0.5 n}
$$

with the subscript $e$ denoting the value for Earth.

Note that this relation specifies the power for a given mass and speed (or the maximum speed for a given power and mass): It does not shed any light on the minimum power required to fly a given mass. By inspection of Eq. (2), this requires the minimization of flight speed and, thus, [Eq. (1)] the maximization of $S C_{L}$. This becomes essentially a structures problem. Applications where this performance is the design driver (high-altitude longendurance aircraft, ${ }^{9}$ human-powered aircraft, and endurance competition model aircraft) typically have unusually high wing mass to dry mass ratios. ${ }^{9}$

Further note that the velocity index of less than unity implies that it is more efficient to fly faster, that is, to accomplish a flight of a given range, the reduction in flying time achieved by flying faster more than not offsets the increased power required to do so. Note, however, that the preceding relation does not apply to jet aircraft.

\section{Lighter-Than-Air Vehicles}

\section{A. Ideal Flight Power for Airships}

Rather than assume a particular envelope shape for a lighterthan-air (LTA) vehicle, let us consider a general scaling, with a characteristic envelope dimension $R$. The volume of the vehicle (neglecting engine appendages, etc.) is, thus, $\alpha R^{3}$, and the drag area is $\beta R^{2}$, with $\alpha$ and $\beta$ constants. Including the lifting gas in the vehicle mass $m$, we have for neutral buoyancy

$$
m=\rho \alpha \cdot R^{3}
$$

with $\rho$ the ambient air density as before. Note that gravity appears on both sides and cancels out.

The flight power is (ignoring propulsion efficiency considerations)

$$
P=D V=\left(0.5 C_{D} \rho \cdot \beta \cdot R^{2} V^{2}\right) V
$$

or

$$
P=0.5 C_{D} \beta \cdot \rho \cdot\left(\frac{m}{\rho \cdot \alpha}\right)^{0.67} V^{.3}
$$

Thus, power is ideally proportional to the cube of flight speed and the two-thirds power of mass. When compared with the corresponding equation for heavier-than-air(HTA) transport, this confirms the intuitive wisdom that lighter-than-air(LTA) vehicles are most useful for large, slow applications.

Interestingly, a weak (one-third power) dependence on atmospheric density remains: Apparently the effort in pushing through a denser medium outweighs the smaller size that such a medium allows. Note, however, that a dense medium offers advantages for real applications, not considered further in this study, via reducing the size and, hence, the envelope, lifting gas, and structural mass. Although higher ambient density requires higher power for a given speed and total mass, the payload mass fraction probably will increase because higher dynamic pressure and, hence, structural loads may partly offset the smaller structural size.

\section{B. Actual Flight Power for Airships}

Data from the real world [Table 2, (see Refs. 6, 7, and 10-15) and

\begin{tabular}{|c|c|c|c|c|c|}
\hline Airship & Power, W & Speed, $\mathrm{m} / \mathrm{s}$ & Mass (kg) & Note & Reference \\
\hline Draganfly & $7.00 E-01$ & 0.8 & $1.00 E-01$ & Radio-control toy & $-{ }^{\mathrm{a}}$ \\
\hline Simon & $2.20 E+02$ & 6.0 & $3.20 E-00$ & Radio-control educational & $-\mathrm{b}$ \\
\hline Wasp & $4.40 E+03$ & 21.1 & $3.40 E+01$ & Unmanned surveillance blimp & $-^{c}$ \\
\hline Blimpguy & $4.85 E+03$ & 12.5 & $8.37 E+01$ & Unmanned surveillance/advertising & ${ }^{\mathrm{d}}$ \\
\hline Zeppy & $1.54 E+02$ & 4.2 & $1.27 E+02$ & Human-powered airship & 7 \\
\hline $\mathrm{D} 2$ & $1.54 E+02$ & 2.5 & $1.82 E+02$ & Human-powered airship & 10 \\
\hline White Dwarf & $1.54 E+02$ & 3.6 & $1.94 E+02$ & Human-powered airship & 7 \\
\hline Baladeuse & $2.57 E+03$ & 6.0 & $2.42 E+02$ & Santos-Dumont no. 9 & 10 \\
\hline Cameron DP60 & $2.10 E+04$ & 7.6 & $5.46 E+02$ & Nonrigid hot air & 11 \\
\hline $\mathrm{ZH} 100$ & $3.13 E+04$ & 8.3 & $6.50 E+02$ & & 11 \\
\hline Aerostatica 02 & $9.54 E+04$ & 25.0 & $7.16 E+02$ & & 11 \\
\hline Auto Blimp & $5.88 E+04$ & 22.3 & $7.73 E+02$ & & 6 \\
\hline SPAS-13 & $7.46 E+04$ & 15.2 & $8.07 E+02$ & Spherical & 11 \\
\hline SASS LITE & $5.88 E+04$ & 20.1 & $8.64 E+02$ & & 6 \\
\hline Ecoblimp N9243S & $3.38 E+04$ & 22.3 & $8.68 E+02$ & & $-\mathrm{e}$ \\
\hline Santos Dumont & $2.94 E+04$ & 13.4 & $1.02 E+03$ & & ${ }^{\mathrm{d}}$ \\
\hline Light Utility & $1.50 E+05$ & 26.1 & $1.44 E+03$ & & $\mathrm{f}^{\mathrm{f}}$ \\
\hline Nulli Secundus & $3.68 E+04$ & 9.8 & $1.74 E+03$ & & 12 \\
\hline La France & $6.25 E+03$ & 6.4 & $2.00 E+03$ & & 12 \\
\hline Lightship A-60+ & $1.00 E+05$ & 23.7 & $2.17 E+03$ & & $\_\mathrm{g}$ \\
\hline SPAS-70 & $2.98 E+05$ & 17.4 & $2.82 E+03$ & Spherical & 11 \\
\hline Lightship A-150 & $2.65 E+05$ & 28.2 & $4.65 E+03$ & & $\ldots \mathrm{g}$ \\
\hline Europa & $3.09 E+05$ & 17.9 & $6.28 E+03$ & & 12 \\
\hline Naval Airship 3 & $2.94 E+05$ & 22.8 & $7.11 E+03$ & & 12 \\
\hline Zeppelin N07 & $4.47 E+05$ & 35.8 & $7.90 E+03$ & & $-\mathrm{e}$ \\
\hline LZ1 & $2.21 E+04$ & 7.6 & $1.24 E+04$ & & 13 \\
\hline LZ3 & $1.54 E+05$ & 12.4 & $1.34 E+04$ & & 13 \\
\hline Italia & $5.51 E+05$ & 25.0 & $2.04 E+04$ & & 12 \\
\hline Bodensee & $7.06 E+05$ & 36.2 & $2.46 E+04$ & & 14 \\
\hline LZ62 & $1.06 E+06$ & 27.7 & $2.79 E+04$ & & 13 \\
\hline Deutschland & $1.06 E+06$ & 16.5 & $6.04 E+04$ & & 14 \\
\hline Sentinel 5000 & $4.48 E+06$ & 45.3 & $7.75 E+04$ & & - $^{\mathrm{e}}$ \\
\hline Akron & $3.29 E+06$ & 35.5 & $2.12 E+05$ & & 15 \\
\hline
\end{tabular}
Fig. 2] at least partially substantiate the given theory. Note in Fig. 2 that the three human-powered airships from Table 2 are circled:

Table 2 LTA vehicles

${ }^{\mathrm{a} U R L}$ :http://www.draganfly.com.

${ }^{b}$ URL:http://www.access.ch/private-users/argon/data.gif.

${ }^{\mathrm{c}}$ URL:http://www.ahausa.com/wasp.html.

${ }^{\mathrm{d}}$ URL:http://www.blimpguys.com/outdoo-lg.html.

${ }^{\text {e} U R L: h t t p: / / w w w . e c o b l i m p . c o m / a i r s h i p . h t m . ~}$

${ }^{\mathrm{f}}$ URL:http://www.ahausa.com/lightutility.html.

${ }^{\mathrm{g}}$ URL:http://www.lightships.com/specifications.html 


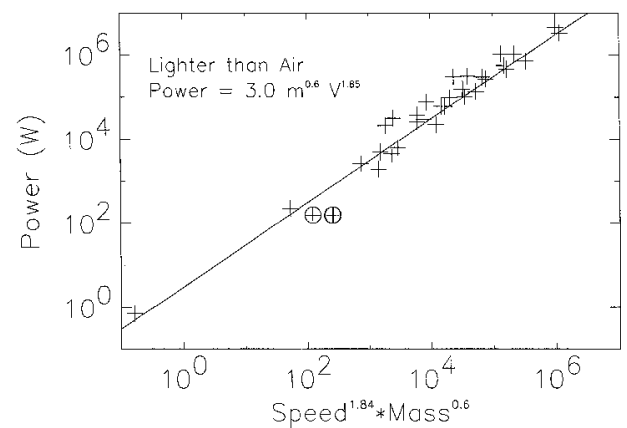

Fig. 2 Installed power on airships as a function of their maximum speed and mass, ranging from a small radio-controlled indoor airship to the mammoth vehicles of the Zeppelin era.

They have somewhat lower power requirements then typical, but the difference is not significant. Regression of installed power data vs mass and maximum speed yields a mass exponent of 0.6 (very close to the 0.67 exponent predicted) and a speed exponent of 1.84 . This is rather lower than the exponent of 3 predicted in Eq. (7), perhaps for two reasons. First, factors mentioned earlier that reduce the exponent for HTA vehicles apply here, too, and second, at their highest speeds, LTA vehicles often generate considerable lift and, thus, may be considered hybrids of ideal LTA and HTA vehicles. The exponent lies between the extreme values for these regimes.

Applying again the environmental dependence to the fit and the propulsive power dependence on density as before, we have

$$
P=3.0 m^{0.6} V^{1.85}\left(\rho / \rho_{e}\right)^{0.33-0.5 n}
$$

Note that human-powered airships appear to be little different from any others in that they fall more or less on the line of fit. Note that the 4- $\mathrm{ft}^{3}$ toy airship (Draganfly) was not included in the dataset for the fit because its performance data was extremely anecdotal (2 AAA size batteries last $45 \mathrm{~min}$, giving a speed of $3 \mathrm{mph}$ ). However, it, too, appears to lie right on the line of fit.

Surprisingly, there appears to be little penalty for the spherical airships, nor for those using helium or hot air instead of hydrogen: They all fall close to the line of fit.

\section{Hover Power and Flight Speed of Helicopters}

An attempt to perform a similar analysis for rotorcraft failed: Evidently rotorcraft are sufficiently complicated (or insufficiently self-similar) for a simple mass/speed scaling to work. Accordingly, we return to theory (e.g., see Ref. 16) and begin with the hover.

We may, to a first order, equate thrust to the vehicle weight $m g$ to compute the required power to hover. Inspection of the installed power for terrestrial rotorcraft (Table 3, see Ref. 17) over a wide range of sizes suggests actuator disk theory applied to hover predicts the required power quite well (see Fig. 3). Most conventional helicopters appear to have installed powers $\sim 100 \%$ larger than predicted, the difference being due to rotor drag, fuselage blockage, and tail rotor power requirements, and that practical aircraft must do more than merely hover. Their peak power is usually required at maximum speed.

A couple of examples appear to have powers lower than that indicated earlier. These are somewhat spurious in that they probably indicate either inaccuracy in the known engine power (or equivalently that higher than rated power is applied in cases of maximum takeoff weight) or rolling takeoff into forward flight is applied in such cases.

There is a perceptible trend that low-mass, that is, small, unmanned, vehicles require a higher thrust margin than conventiona manned helicopters. This is likely due to higher inefficiencies due to low Reynolds number and increased fuselage blockage for small vehicles.

The required powers are fit, as a function of vehicle mass with (Fig. 4)

$$
P=100 m^{1.1}
$$

The exponent of $\sim 1$ is lower than the 1.5 from the actuator disk equation. The reason is simply that more massive vehicles also have

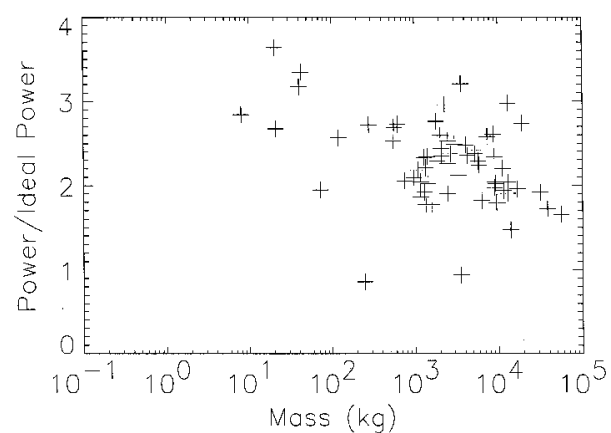

Fig. 3 Installed power for rotorcraft divided by the ideal (actuator disk) power as a function of vehicle mass.

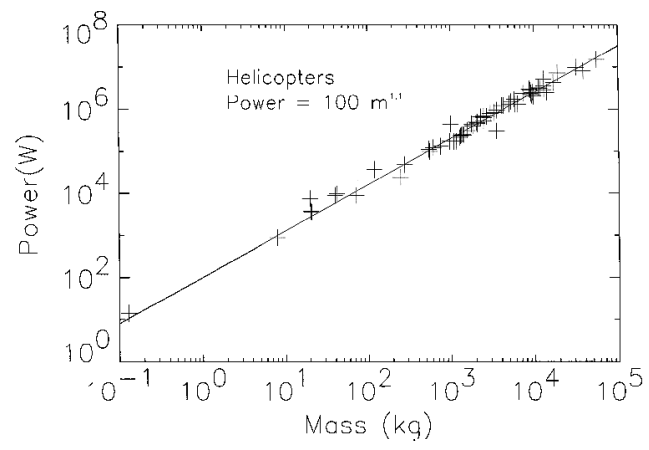

Fig. 4 Installed engine power for small terrestrial rotorcraft vs their mass; all of these are conventional helicopters, with the exception of the Sikorsky Cypher (an urban warfare prototype vehicle), which uses a ducted fan.

larger rotors: Regression (not shown) indicates that the rotor diameter scales as $m^{0.4}$ or, equivalently, the disk area scales as $m^{0.8}$, presumably at least partly because of structural engineering considerations. Thus, the scaling of rotor diameter offsets part of the power growth to leave power roughly proportional to mass.

In another planetary environment, the substitution of density and gravity is straightforward and is guided by the actuator disk equation (3). For a given vehicle mass, the weight (or required thrust) is proportional to gravity such that a sevenfold reduction in gravity, for example, going from Earth to Saturn's moon Titan, results in a remarkable $7^{1.5}(=19$-fold) reduction in power requirement. In summary, the power requirement for a typical helicopter is

$$
P=100 \mathrm{~m}^{1.1}\left(\mathrm{~g} / \mathrm{g}_{e}\right)^{1.5}\left(\rho_{e} / \rho\right)^{0.5}
$$

In steady level flight, the rotor is tilted at an angle $\gamma$, such that drag $D=T \sin \gamma$, with $T$ the thrust and weight $m g=T \cos \gamma$. Making the small angle approximation $\cos \gamma=1-\gamma^{2} / 2$, we obtain

$$
\gamma \approx(1-m g / T)^{0.5}
$$

We may relate drag to the dynamic pressure of forward flight multiplied by an area and a drag coefficient. The drag area may be related (assuming a constant geometry and constant density) to the twothirds power of mass. Lumping the drag and geometric coefficients together, we then obtain on substitution

$$
\rho V^{2} m^{0.67} \propto T(1-m g / T)^{0.5}
$$

Sacrificing accuracy for convenience, we may use the thrust provided at maximum power by the actuator disk equation to predict the maximum speed given earlier, namely,

$V_{\max }=k\left\{P^{0.66} A^{0.33} m^{-0.67} \rho^{-0.67}\left[1-m g /\left(P^{0.66} A^{0.33} \rho^{0.33}\right)\right\}^{0.5}\right.$

The real-world data (Fig. 5) shows a performance envelope that indeed seems to be bounded for lower speeds by this relation, although many vehicles have poorer performance than this limit.

The data level out at a speed of $100 \mathrm{~m} / \mathrm{s}$, due to the problems of asymmetric lift generation and tip Mach number, but otherwise the stated maximum speed is directly proportional to the term on the right-hand side, with a constant of proportionality $k$ of about 8 
Table 3 Rotorcraft

\begin{tabular}{|c|c|c|c|c|c|}
\hline Helicopter & Power, W & $\begin{array}{l}\text { Maximum speed, } \\
\mathrm{m} / \mathrm{s}\end{array}$ & $\begin{array}{l}\text { Maximum takeoff mass, } \\
\mathrm{kg}\end{array}$ & $\begin{array}{c}\text { Rotor } \\
\text { diameter, } \mathrm{m}\end{array}$ & Reference \\
\hline Pixel & $1.4 E+01$ & 8.9 & $1.29 E-01$ & 0.4 & $-^{\mathrm{a}}$ \\
\hline RCS Small & $8.8 E+02$ & 31.3 & $8.00 E+00$ & 1.6 & 5 \\
\hline RCS Large & $7.4 E+03$ & 16.7 & $2.00 E+01$ & 2.3 & 5 \\
\hline Hummingbird & $3.7 E+03$ & 13.4 & $2.05 E+01$ & 2.0 & 6 \\
\hline Vigilant & $8.8 E+03$ & 26.8 & $4.00 E+01$ & 2.0 & 6 \\
\hline Barstow Mi24D & $9.6 E+03$ & 31.3 & $4.23 E+01$ & 2.1 & 6 \\
\hline CMU & $8.8 E+03$ & 38.0 & $7.27 E+01$ & 3.0 & 17 \\
\hline Cypher & $3.7 E+04$ & 41.2 & $1.20 E+02$ & 2.0 & 6 \\
\hline $\mathrm{Ka} 37$ & $2.4 E+04$ & 30.4 & $2.50 E+02$ & 3.1 & 6 \\
\hline Ka 137 & $4.8 E+04$ & 42.5 & $2.80 E+02$ & 5.8 & 6 \\
\hline G2 Cabri & $1.1 E+05$ & 55.6 & $5.50 E+02$ & 6.5 & 8 \\
\hline $\mathrm{R} 22$ & $1.2 E+05$ & 50.0 & $6.21 E+02$ & 7.7 & 8 \\
\hline Brantly B2 & $1.3 E+05$ & 44.7 & $7.57 E+02$ & 7.2 & 8 \\
\hline Schweitzer 300 & $1.7 E+05$ & 34.4 & $9.75 E+02$ & 8.2 & 8 \\
\hline Seamos & $4.4 E+05$ & 17.9 & $1.00 E+03$ & 6.7 & 8 \\
\hline R44 & $1.7 E+05$ & 58.1 & $1.09 E+03$ & 10.1 & 8 \\
\hline Enstrom F-28 & $1.7 E+05$ & 52.5 & $1.18 E+03$ & 9.7 & 8 \\
\hline Bell 47 & $2.1 E+05$ & 46.9 & $1.29 E+03$ & 11.3 & 8 \\
\hline Brantly 305 & $2.3 E+05$ & 53.6 & $1.32 E+03$ & 8.7 & 8 \\
\hline Mi-34 Hermit & $2.4 E+05$ & 61.1 & $1.35 E+03$ & 10.0 & 8 \\
\hline MD 500 & $2.4 E+05$ & 67.8 & $1.36 E+03$ & 8.1 & 8 \\
\hline Hiller UH-12E & $2.5 E+05$ & 40.3 & $1.41 E+03$ & 10.8 & 8 \\
\hline Bell 206 & $2.4 E+05$ & 62.5 & $1.45 E+03$ & 10.2 & 8 \\
\hline MD 500E & $3.1 E+05$ & 78.3 & $1.61 E+03$ & 8.1 & 8 \\
\hline Gazelle & $4.4 E+05$ & 86.1 & $1.80 E+03$ & 10.5 & 8 \\
\hline Ka 115 & $4.0 E+05$ & 61.7 & $1.85 E+03$ & 10.0 & 8 \\
\hline Kiowa & $4.9 E+05$ & 65.8 & $2.04 E+03$ & 10.7 & 8 \\
\hline Alouette III & $4.5 E+05$ & 61.1 & $2.10 E+03$ & 11.0 & 8 \\
\hline Squirrel & $4.8 E+05$ & 79.7 & $2.10 E+03$ & 10.7 & 8 \\
\hline Alouette II & $6.5 E+05$ & 58.3 & $2.30 E+03$ & 11.0 & 8 \\
\hline Westland Wasp & $5.3 E+05$ & 53.6 & $2.50 E+03$ & 9.8 & 8 \\
\hline Bo 105 & $6.3 E+05$ & 66.7 & $2.50 E+03$ & 9.8 & 8 \\
\hline Bo EC 135 & $6.8 E+05$ & 75.0 & $2.50 E+03$ & 10.2 & 8 \\
\hline Agusta A109 & $6.7 E+05$ & 86.4 & $2.72 E+03$ & 11.0 & 8 \\
\hline Dauphin & $7.8 E+05$ & 87.5 & $3.00 E+03$ & 11.5 & 8 \\
\hline BK 117 & $8.2 E+05$ & 77.2 & $3.35 E+03$ & 11.0 & 8 \\
\hline Mi-2 Hoplite & $3.0 E+05$ & 55.6 & $3.55 E+03$ & 14.5 & 8 \\
\hline Sikorsky S-62 & $9.3 E+05$ & 45.3 & $3.58 E+03$ & 16.2 & 8 \\
\hline Mangusta & $1.2 E+06$ & 81.7 & $4.10 E+03$ & 11.9 & 8 \\
\hline Panther & $1.2 E+06$ & 82.2 & $4.25 E+03$ & 11.9 & 8 \\
\hline Bell 212 & $1.3 E+06$ & 51.4 & $5.08 E+03$ & 14.7 & 8 \\
\hline Sikorsky S-76 & $1.5 E+06$ & 79.7 & $5.31 E+03$ & 13.4 & 8 \\
\hline Tiger & $1.7 E+06$ & 77.8 & $5.80 E+03$ & 13.0 & 8 \\
\hline Sikorsky S-58 & $1.3 E+06$ & 61.7 & $5.90 E+03$ & 17.1 & 8 \\
\hline PZL W-3 & $1.3 E+06$ & 70.8 & $6.40 E+03$ & 15.7 & 8 \\
\hline Puma & $2.4 E+06$ & 75.3 & $7.40 E+03$ & 15.0 & 8 \\
\hline Rooivalk & $3.0 E+06$ & 85.8 & $8.75 E+03$ & 15.6 & 8 \\
\hline Super Puma & $2.8 E+06$ & 77.2 & $9.00 E+03$ & 15.6 & 8 \\
\hline NH 90 & $2.3 E+06$ & 83.3 & $9.10 E+03$ & 16.3 & 8 \\
\hline Sikorsky S-70 & $2.4 E+06$ & 82.2 & $9.19 E+03$ & 16.4 & 8 \\
\hline Sikorsky S-61 & $2.1 E+06$ & 74.2 & $9.30 E+03$ & 18.9 & 8 \\
\hline AH-64 Apache & $2.5 E+06$ & 101.4 & $9.53 E+03$ & 14.6 & 8 \\
\hline Wessex & $2.0 E+06$ & 62.8 & $9.75 E+03$ & 18.9 & 8 \\
\hline Mi-24 Hind & $3.3 E+06$ & 93.1 & $1.12 E+04$ & 17.3 & 8 \\
\hline Mi-28 Havoc & $3.1 E+06$ & 83.3 & $1.17 E+04$ & 17.2 & 8 \\
\hline EH101 & $5.2 E+06$ & 85.8 & $1.30 E+04$ & 18.6 & 8 \\
\hline Mi-8 Hip & $2.9 E+06$ & 69.4 & $1.30 E+04$ & 21.3 & 8 \\
\hline Frelon & $3.5 E+06$ & 76.4 & $1.30 E+04$ & 18.9 & 8 \\
\hline Mi-14 Haze & $2.5 E+06$ & 63.9 & $1.40 E+04$ & 21.3 & 8 \\
\hline Sikorsky S-65 & $4.3 E+06$ & 83.1 & $1.70 E+04$ & 22.0 & 8 \\
\hline Sikorsky S-64 & $7.2 E+06$ & 56.4 & $1.91 E+04$ & 21.9 & 8 \\
\hline Sikorsky S-80 & $9.8 E+06$ & 87.5 & $3.16 E+04$ & 24.1 & 8 \\
\hline Mi-6 Hook & $8.1 E+06$ & 83.3 & $3.84 E+04$ & 35.0 & 8 \\
\hline Mi-26 Halo & $1.5 E+07$ & 81.9 & $5.60 E+04$ & 32.0 & 8 \\
\hline
\end{tabular}

${ }^{\mathrm{a} U R L: h t t p: / / w w w . p l a n e t i n t e r n e t . b e / p i x e l . ~}$

for the highest-performancerotorcraft and a factor of about 2 lower than that for slow vehicles

\section{Application}

\section{A. Bird Migration Range}

The preceding relations may be applied to determine the range, making some very crude approximations. Neglecting mass changes, for example, we may estimate the range of a migrant bird, ${ }^{2}$ the
Pacific golden plover. This $\sim 130-\mathrm{g}$ bird migrates $3900 \mathrm{~km}$ on a fat content of $\sim 25 \%$

Fat has an energy content of $39 \mathrm{~kJ} / \mathrm{g}$, and if we assume a typical energy to work conversion efficiency of $20 \%$, the bird has $\sim 1 \mathrm{MJ}$ of mechanical energy available. If it flies at $\sim 10 \mathrm{~m} / \mathrm{s}$, then using the equation for HTA fixed-wing aircraft, we would predict a flight power of $\sim 13 \mathrm{~W}$. Thus, it can fly for about $24 \mathrm{~h}$, achieving a still-air range of $\sim 700 \mathrm{~km}$. 


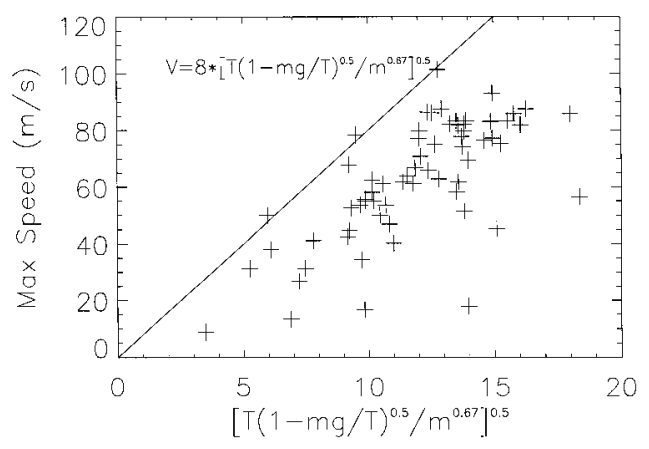

Fig. 5 Maximum speed of helicopters as a function of their maximum takeoff mass and installed power; line indicates an approximate maximum speed limit described in the text.

That the aerodynamics of birds is more appropriately described by helicopter aerodynamics than by fixed-wing aerodynamics has been long noted. ${ }^{18,19}$ Solving Eq. (12) by trial and error, we see that to fly at $10 \mathrm{~m} / \mathrm{s}$ a $130-\mathrm{g}$ bird with a wingspan of $45 \mathrm{~cm}$ requires a thrust of $1.4 \mathrm{~N}$, that is, a thrust/weight ratio of 1.1 , requiring a (mechanical) power of only $2.7 \mathrm{~W}$. It can, thus, fly for about 3 days, with a range of $3700 \mathrm{~km}$, which shows very good agreement.

The agreement is probably fortuitous because even regression of statistics of birds ${ }^{2}$ alone fails to predict the remarkable range of migrant birds, which probably are very careful to take advantage of tailwinds. However, even an order-of-magnitude agreement would have been encouraging.

\section{B. Terrestrial Submarines}

Although there are no examples at hand where the gravitational environment of a vehicle is different from that on Earth, the Earth's oceans provide a convenient alternate environment, with a medium density some 800 times larger than air. This provides us with an opportunity to test the relationships for LTA vehicles.

As an example, consider the submarine Sailfish (submerged speed $10 \mathrm{kn}$ and displacement 3168 ton) Applying Eq. (8) with $n=0$ yields a power of $47 \mathrm{MW}$. Applying $n=1$ instead, that is, a factor $\left(800^{0.5}\right)=28$ reduction in power, yields $1.8 \mathrm{MW}$. This compares quite well with the installed power of $6 \mathrm{MW}$, and it is comforting that the result lies between the two extremes of $n=0$ and $n=1$.

\section{Application: To Fly or to Float?}

Equating the two expressions(4) and (8) for installed power yields the break-even relation

$$
V=3.6\left(\rho / \rho_{e}\right)^{-0.32}\left(g / g_{e}\right) m^{0.19}
$$

which defines the earlier flight speed that a given mass vehicle will be more efficiently flown with an HTA configuration.

Plotting the real-world data against this relation (Fig. 6) broadly bears this out. All HTA vehicles (filled circles) fall above the line and require lower power than LTA (open circles) vehicles. Interestingly, several of the LTA vehicles also appear above the line, presumably because the LTA vehicle is not optimized by this criterion. Simply because an HTA vehicle can fly with a lower power for the same mass and top speed as a given LTA vehicle does not mean it can do the same job: An LTA vehicle may offer advantages in endurance, noise, aesthetics, or the ability to fly slowly, which will outweigh its inefficiency. Also note from Fig. 6 that the HTA aircraft studied have maximum speeds approximately three times faster than break even.

\section{Application: Aeronautics on Mars}

There has been recent interest from NASA in sending an aircraft to fly in the Martian atmosphere in 2005, although ideas about flying in the Martian atmosphere date back at least back to Von Braun. ${ }^{20}$ Atmospheric density is only 0.017 or 60 times lower than Earth sea level. The only kindness offered to astronauts is that Martian gravity is $3.8 \mathrm{~ms}^{-2}$, or about three-eighths that of Earth.

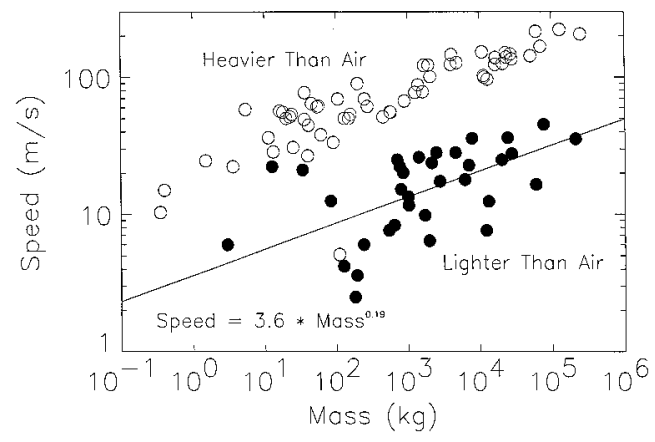

Fig. 6 Line shows the mass/velocity relation for which LTA and HTA vehicles require the same power.

From these considerations, power for HTA flight is reduced by the low gravity, whereas that for LTA flight is also reduced by the low density. When Eq. (14) is applied, the break-even speed is increased by about $60 \%$, to $5.6 m^{0.19}$. The thin air does, however, force aircraft to have low wing loading and high flight speed, or LTA aircraft to have very large envelopes. A directed LTA needs also to have a high speed, because Martian winds are strong. The low air density also has a severe impact on propulsive power, assuming $n>0$.

Morrissette and DeLaurier ${ }^{21}$ recently described a design for a crewed Mars aircraft, as a vehicle for future exploration of Mars. Their detailed study developed a twin-boom design (like the Voyager around-the-world aircraft) but with a biplane wing: Its weight of 2000 Mars pounds implies a mass of $2410 \mathrm{~kg}$. At zero altitude (the 6 -mbar reference level), its top speed with a power of $58 \mathrm{hp}(41 \mathrm{~kW})$ would be $204 \mathrm{kn}(105 \mathrm{~m} / \mathrm{s})$.

Plugging the speed and mass into our relation for power [Eq. (4)] gives $62 \mathrm{~kW}$ for $n=0$, a not unreasonable estimate given that the design is highly optimized. The authors undertook a specific propeller design optimization (coming up with a sizeable 4-m-diam propeller), and so $n=0$ is perhaps not inappropriate: $n=1$ would imply an improbably small propeller, with a factor 9 increase in required power.

Other Martian airplane studies have not undertaken propeller optimization and simply calculate propulsive power from the required thrust and flight speed, with an assumed (high) propeller efficiency. Clapp $^{22}$ explores a Gossamer Albatross-like Mars aeroplane with a mass of $1000 \mathrm{~kg}$ and a $42-\mathrm{m}$ span. When an $L / D$ of 35 and a propulsion efficiency of 0.88 is assumed, he computes a flight power of $8.8 \mathrm{~kW}$ at $70 \mathrm{~m} / \mathrm{s}$. Use of Eq. (4) suggests that a result between $48 \mathrm{~kW}(n=0)$ and $434 \mathrm{~kW}(n=1)$ is more likely.

Augenstein ${ }^{23}$ considers a $300-\mathrm{kg}$ aircraft with an $L / D$ of 30 and computes a power of $1.9 \mathrm{~kW}$. Use of Eq. (4) suggests $15-213 \mathrm{~kW}$ (he assumes a Mars altitude of $10 \mathrm{~km}$, thus a lower density than before, so that the $n=1$ case is about 14 times higher than $n=0$, rather than 9 times higher).

Clapp $^{22}$ also considers an airship, again $1000 \mathrm{~kg}$, with a flight speed of $5.1 \mathrm{~m} / \mathrm{s}$, and computes a power requirement of $13.7 \mathrm{~kW}$. Use of Eq. (8) suggests only $890 \mathrm{~W}(n=0)$, or a more plausible $8.8 \mathrm{~kW}$ for $n=1$. Girerd ${ }^{24}$ also studies an airship, $200 \mathrm{~kg}$ in mass traveling at $10 \mathrm{~m} / \mathrm{s}$. From the fuel parameters, one may infer a flight power of $900 \mathrm{~W}$ : Use of Eq. (8) suggests from $1200 \mathrm{~W}(n=0)$ to $11 \mathrm{~kW}(n=1)$.

Two authors ${ }^{22,25}$ propose hybrid aircraft (partially buoyant inflatable airplanes). Clapp ${ }^{22}$ considers a $1000-\mathrm{kg}$ vehicle developing $15 \%$ of its weight by buoyancy and flying at $26 \mathrm{~m} / \mathrm{s}$, calculating a power of $11 \mathrm{~kW}$. Interestingly, this vehicle is near the break-even point. Use of Eqs. (4) and (8) predict HTA and LTA powers of 20 and $18 \mathrm{~kW}(n=0)$, respectively, or nine times this value for $n=1$. Finally, Gundlach ${ }^{25}$ considers a $4.8 \%$ buoyant $50-\mathrm{kg}$ vehicle at $24 \mathrm{~m} / \mathrm{s}$. He performs a propeller study (yielding a 12-m span vehicle with 3 -m-diam propellers) requiring $714 \mathrm{~W}$ to fly. Again, where a propeller study has been made, the results are within a reasonable factor of $\sim 3$ of Eqs. (4) and (8) for $n=0(2.6$ and $1.6 \mathrm{~kW}$, respectively). 
Some aspects of rotorcraft in the Martian atmosphere were explored by Savu et al., ${ }^{26}$ although no credible design was advanced. Recently, local topographic mapping by a laser line scanner has been demonstrated by an unmanned helicopter at the Devon Island (Canadian Arctic) Mars analog site. Although there has been considerable progress in the control and operational aspects, implementation of such a vehicle on Mars still presents significant airframe/power problems: The 80 -fold lower atmospheric density more than offsets the effects of lower gravity. Even ignoring the reduced efficiency due to low Reynolds number, the power for a given mass and rotor diameter vehicle to hover are higher by at least a factor of 2 .

\section{E. Application: Aeronautics on Titan}

Saturn's giant moon Titan is an aeronaut's paradise, with a thick atmosphere (density is four times that at Earth sea level) and a low gravity $\left(1.35 \mathrm{~m} / \mathrm{s}^{2}\right)$. An early study by Friedlander ${ }^{27}$ suggests balloons and dirigibles as Titan exploration vehicles, but does not explore propulsion in any detail. Zubrin ${ }^{28}$ has made the observation that human beings with wings strapped to their arms could fly; substitution of plausible values in Eq. (3) indeed suggests this could be the case.

More practicably, a small (20-100 kg) unmanned aerial vehicle (UAV) would be the next logical step in Titan exploration after the Cassini mission presently en route (featuring a parachute-borne Titan probe). An aerial vehicle could survey the entire surface at higher resolutions than is possible from orbit and access surface sites for chemical sampling.

A reasonable flight speed requirement would be $\sim 1 \mathrm{~m} / \mathrm{s}$, giving the ability to traverse pole to pole twice in one year (and, thus, because there are east-west winds that are strong at altitude, access to anywhere on the surface). At the $\sim 1-\mathrm{m} / \mathrm{s}$ speed, the flight power required is about the same for HTA and LTA and, thus, does not argue strongly for either type. For 20- and 100-kg vehicles, this is then $\sim 10$ and $30-40 \mathrm{~W}$, respectively, from Eqs. (4) and (8).

Flight at low speed, even in Titan's low gravity and dense atmosphere, requires large wings. The wing loading $\left(\mathrm{m} / S C_{L}\right)$ for flight near Titan's surface at $1 \mathrm{~m} / \mathrm{s}$ is only about $2 \mathrm{~kg} / \mathrm{m}^{2}$ : Because a maximum lift coefficient of $\sim 1$ is typical, this requires wings of $>10 \mathrm{~m}^{2}$ of area for the $20-\mathrm{kg}$ vehicle. This may be compared with the wing loading on typical terrestrial aircraft of $>100 \mathrm{~kg} / \mathrm{m}^{2}$. In fact, the Titan aircraft resembles more the case of a human-powered aircraft such as the Gossamer Albatross of $\sim 5 \mathrm{~kg} / \mathrm{m}^{2}$ or a paper dart of $0.5 \mathrm{~kg} / \mathrm{m}^{2}$. The former was very delicate, and its structure would not be amenable to packaging and delivery to another planetary body. The latter is perhaps a poor example in that it is $>3$ orders of magnitude smaller than we are considering and does not scale up well (in fact a simple experiment will show that even scaling up by a factor of 2 can introduce severe aeroelasticity problems). The Pathfinder high-altitude solar unmanned aircraft is an appropriate analog and is the state of the art.

A fortunate corollary of the low wing loading is that if such an aircraft can be built, it should be able to access the surface easily: By simply stalling out, it would parachute to the ground with a terminal speed of a gentle $1 \mathrm{~m} / \mathrm{s}$ or so. A pressurized, inflatable airframe might be able to provide the required stiffness for low mass and be readily accommodated on an entry vehicle. However, perhaps an LTA vehicle would be a more practicable alternative.

Another option might be to use a rotorcraft. This exploits both of Titan's environmental advantages. A 100-kg helicopter on Titan [from Eq. (3)] could hover with a power of only $450 \mathrm{~W}$ and would be easily able to access surface materials for sampling. Scientific considerations and candidate mission profiles for Titan exploration vehicles are considered in a separate paper. ${ }^{29}$

\section{Conclusions}

Relations have been developed for estimating the power required for HTA and LTA flight as a function of flight speed and mass. They provide a zeroth-order performance estimate. What they lack in accuracy, these relations make up for in convenience and offer some insight into the selection of the best type of vehicle for a given application.

Relatively few vehicles significantly outperform the relations presented here; any that do so might require an explanation of why, for example, slow-flying human-powered aircraft with efficient propellers and very low wing loading. The relations can be adjusted for other planetary environments, although there is some uncertainty as to quite how the propulsion system (specifically propeller diameter) should scale. The examples considered suggest that many studies to date may sorely underestimate the propulsive power requirements for Mars aircraft.

\section{Acknowledgment}

A hard copy of the Web site materials is held by the author and is available on request.

\section{References}

${ }^{1}$ Raymer, D., Aircraft Design: A Conceptual Approach, AIAA, Washington DC, 1992.

${ }^{2}$ Calder, W. A., III, Size, Function and Life History, Dover, New York, 1996

${ }^{3}$ von Kármán, T., and Gabrielli, G., "What Price Speed? Specific Power Required for Propulsion of Vehicles," Mechanical Engineering, Vol. 12, 1950, pp. 775-571; Collected Works of Von Kármán, Vol. 4.

${ }^{4}$ Rais-Rohani, M., and Hicks, G. R., "Multidisciplinary Design and Prototype Development of a Micro Air Vehicle," Journal of Aircraft, Vol. 36, No. 1, 1999, pp. 227-234.

5 Taylor, J. W. R. (ed), Jane's Pocket Book of Remotely Piloted Vehicles, Macmillan, New York, 1977.

${ }^{6}$ Aviation Week and Space Technology, Jan. 11, 1999.

${ }^{7}$ Allen, B. L., "White Dwarf and Pedal-Powered Flight," AIAA Student Journal, Summer, 1988, pp. 6-12.

${ }^{8}$ Jane's Aircraft Recognition Guide, Janes, 1997

${ }^{9}$ Jones, R. L., "The Design Challenge of High Altitude Long Endurance (Hale) Unmanned Aircraft," Aeronautical Journal, Vol. 103, No. 1024, 1999, pp. 273-280.

${ }^{10}$ Dorrington, G. E., "Development of Human-Powered Airships in Southampton 1991-1993," International Airship Conf., Stuttgart, June 1993. ${ }^{11}$ Jane's All The World's Aircraft, 1998-1999.

${ }^{12}$ Lord Ventry and Kolesnik, E. M., Airship Saga, Blandford, Poole, England, U.K., 1982.

${ }^{13}$ Chamberlain, G., Airships at Cardington, Terence Dalton, Lavenham, 1984.

${ }^{14}$ Kleinheins, P., Die Grossen Zeppeline, VDI Verlag, Dusseldorf, Germany, 1985.

${ }^{15}$ Payne, L., Lighter than Air: An Illustrated History of the Airship, A. J. Barnes, NJ, 1977.

${ }^{16}$ Newman, S., Foundations of Helicopter Flight, Edward Arnold, London, 1994.

${ }^{17}$ Amidi, O., Kanade, T., and Fujita, K., "A Visual Odometer for Autonomous Helicopter Flight," Robotics and Autonomous Systems, Vol. 28, No. 2, 1999, pp. 185-195.

${ }^{18}$ Pennycuick, C. J., Bird Flight Performance: A Practical Calculation Manual, Oxford Univ. Press, Oxford, England, U.K., 1989.

${ }^{19}$ Rayner, J. M. V., "The Mechanics of Flight and Bird Migration," Bird Migration, edited by E. Gwinner, Springer-Verlag, Berlin, 1990.

${ }^{20}$ Von Braun, V., Das Marsprojekt, Bechte Verlag, Esslingen, Germany, 1952.

${ }^{21}$ Morrissette, B. R., and DeLaurier, J. D., "The Zephyr: Manned Martian Aircraft," Canadian Aeronautics and Space Journal, Vol. 45, No. 1, 1999, pp. 25-31

${ }^{22}$ Clapp, W. M., "Dirigible Airships for Martian Surface Exploration," The Case for Mars II, Vol. 62, American Astronautical Society Science and Technology Series, 1984, pp. 489-496.

${ }^{23}$ Augenstein, B. W., "The Mars Airplane Revived-Global Mars Surface Surveys," The Case for Mars III, Vol. 75, American Astronautical Society Science and Technology Series, 1987, pp. 547-556.

${ }^{24}$ Girerd, A. R., "The Case for a Robotic Martian Airship," 12th Lighter Than Air Systems Technology Conf., June 1987.

${ }^{25}$ Gundlach, J. F., IV, "Unmanned Solar-Powered Hybrid Airships for Mars Exploration,” AIAA Paper 99-896, Jan. 1999.

${ }^{26}$ Savu, G., Trifu, O., and Oprisiu, C., "An Autonomous Flying Robot for Mars Exploration," 44th Congress of the International Astronautical Federation, IAF Rept. 93-U.4.568, Oct. 1993.

${ }^{27}$ Friedlander, A. L., "Titan Buoyant Station," Journal of the British Interplanetary Society, Vol. 37, 1984, pp. 381-387.

${ }^{28}$ Zubrin, R., “The Case for Titan,” Ad Astra, June 1991, pp. 36-30.

${ }^{29}$ Lorenz, R., "Post-Cassini Exploration of Titan: Science Rationale and Mission Concepts," Journal of the British Interplanetary Society, Vol. 53, No. 7/8, 2000, pp. 218-234. 